\title{
TRANSFORMASI NOVEL KE FILM 99 CAHAYA DI LANGIT EROPA KARYA HANUM SALSABILA RAIS DAN RANGGA ALMAHENDRA (KAJIAN INTERTEKSTUAL)
}

\author{
Imelda Ratih Ayu \\ Emai: Imeldaratihayu@Univpgri-palembang.ac.id \\ Universitas PGRI Palembang
}

\begin{abstract}
Abstrak -- Penelitian ini bertujuan untuk mengetahui bagaimana transformasi novel ke film 99 Cahaya di Langit Eropa karya Hanum salsabila dan Rangga Almahendra berdasarkan kernel dan satelit. Rumusan masalah dalam penelitian ini adalah, (1) Kernel dan satelit novel "99 Cahaya di Langit Eropa" selaku hipogram dari film "99 Cahaya di Langit Eropa", (2)Kernel dan satelit film "99 Cahaya di Langit Eropa" sebagai hasil transformasi terhadap novel aslinya, (3)Perbedaan alur pada tranformasi novel dan film "99 Cahaya di Langit Eropa" berdasarkan kernel dan satelit. Metode yang digunakan dalam penelititian ini adalah metode deskriftif kualitatif. Berdasarkan hasil penelitian mengenai kernel dan satelit novel 99 Cahaya di Langit Eropa karya Hanum Salsabila dan Rangga Almahendra dapat diperoleh data kernel sebanyak 31 kernel dan satelit sebanyak 62 satelit, sedangkan data film 99 Cahaya di Langit Eropa menunjukan jumlah kernel sebanyak 40 kernel dan satelit sebanyak70 satelit.
\end{abstract}

Kata Kunci : Tranformasi, Kernel dan Satelit

Abstract -- This study aims to determine how the transformation of the novel into the film 99 Cahaya di Langit Europe by Hanum Salsabila and Rangga Almahendra based on kernels and satellites. The formulations of the problems in this study are, (1) Kernel and the satellite of the novel "99 Lights in the European Sky" as the hypogram for the film "99 Lights in the European Sky", (2) Kernel and the satellite film "99 Lights in the European Sky" as a result of transformation towards the original novel, (3) The different plot in the transformation of the novel and the film "99 Lights in the European Sky" based on the kernel and satellite. The method used in this research is a qualitative descriptive method.Based on the results of research on the kernel and satellite of the novel 99 Cahaya di Langit Europe by Hanum Salsabila and Rangga Almahendra, 31 kernels and 62 satellites can be obtained, while the 99 Cahaya di Langit film data shows the number of kernels as many as 40 kernels and 70 satellites., and the difference in storylines in the transformation of the novel.

Keywords: Transformation, Kernel and Satellit. 


\section{PENDAHULUAN}

Fenomena mengenai novel yang difilmkan kini semakin mencuat di kalangan masyarakat. Hal ini menimbulkan rasa penasaran pembaca, apakah novel yang difilmkan akan sama dengan isi novelnya atau tidak. Fenomena ini terjadi karena kesuksesan sebuah novel yang berhasil diminati oleh masyarakat luas dan biasanya mengalami cetakan ulang hingga berkali-kali sehingga membuat produser film tertarik untuk melayarputihkan novel tersebut dengan berbagai tujuan, yaitu merealisasikan imaji pembaca hingga ingin mengulang kesuksesan dari novel tersebut.

Film yang diadaptasikan dari sebuah novel menimbulkan berbagai respons dari pembaca. Ada beberapa pembaca dengan respon positif yaitu merasa puas setelah menonton film yang dialihwahanakan karena isi film sesuai dengan isi novel ataupun isi film sesuai dengan imaji pembaca dan ada pula respon negatif yaitu kekecewaan yang ditimbulkan karena tidak sesuai dengan imaji pembaca. Di Indonesia, proses transformasi dari novel ke film memunculkan beragam film layar lebar seperti Ayat-Ayat Cinta karya Hanung Bramantyo yang diangkat dari novel karya Habiburrahman El Shirazy, film Laskar Pelangi karya Riri Riza yang diangkat dari novelLaskar Pelangi karya Andre Hirata, atau Film Eiffel I'm In Love karya Nesry Cheepy yang diangkat dari novel karya Rachmania Arunita.

Umumnya film-film yang diangkat dari novel melibatkan dua orang penting yaitu pengarang dan sutradara. Cerita dalam novel ditentukan oleh sudut pandang pengarang, sementara cerita dalam film diatur oleh sutradara.Dengan demikian, ketika novel difilmkan maka cerita atau kisah yang diceritakan tidak lagi bertolak pada sudut pandang pengarang melainkan berpindah sudut pandang sutradara.Sudut pandang pengarang dan sudut pandang sutradara jelas berbeda.Sudut pandang pengarang berpusat pada kualitas novel dan seni bahasa, sedangkan sudut pandang sutradara berpusat pada kualitas film dan untuk kepentingan komersial. Tidak heran, jika antara novel dan filmnya banyak perbedaan. Banyak peristiwa dalam novel tidak ditayangkan pada filmnya dan banyak pula peristiwa yang tidak ada dalam novel tetapi dalam filmnya ada. Ini semua tidak terlepas dari andil sutradara yang mengambil alih pemikiran ide.

Perbedaan-perbedaan yang terjadi antara film dan novel yang diadaptasinya, menurut Eneste (1991:61-65), merupakan proses kreatif 
yang dapat dilakukan oleh sutradara dengan cara mengadakan penambahan, pengurangan, dan pemunculan variasi-variasi alur cerita. Bermacam-macam penambahan, pengurangan, dan pemberian variasivariasi tersebut adalah sebagai akibat medium yang berbeda(jika film menggunakan medium gambar dan musik maka novel menggunakan medium bahasa), antara film hasil transformasi dengan novel yang diadaptasi, sehingga mengakibatkan terjadinya perubahan fungsi khususnya dalam alur cerita. Asumsi adanya perbedaan tersebut yang menjadi objek formal dalam penelitian ini.

Peneliti mengambil novel 99 Cahaya di Langit Eropa karya Hanum Salsabilah yang diterbitkan pada tahun 2013 dan film 99 Cahaya dari Langit Eropa karya Guruh Soeharjanto pada tahun 2013 karena beberapa alasan. Pertama, terdapat perbedaan pada alur, penokohan, latar ruang dan waktu antara kedua karya sastra tersebut. Kedua, novel tersebut adalah salah satu novel Best Seller.Peneliti menganalisis novel yang diadaptasi dan film adaptasinya dengan menempatkan keduanya sebagai sebuah sistem sastra dan sistem film. Sistem yang dianalisis adalah alur cerita keduanya, ditinjau dari kernel dan satelitnya, sehingga diperoleh perubahan fungsi yang terjadi pada film. Perubahan fungsi itulah yang menghasilkan beragam perbedaan antara kedua karya sastra tersebut dan merupakan proses pentransformasian.

Proses telaah sistem sastra dan sistem film difokuskan pada kernel (kernel) dan satelit (satellite) novel dan film yang berdasarkan pada pemikiran Chatman menempatkan novel dan film pada posisi imbang dan sejajar, yaitu meletakkan keduanya sebagai suatu struktur naratif. Hal itulah yang menyebabkan sistem sastra dan sistem film dapat dianalisis dengan mempergunakan kaidah masingmasing. Selanjutnya, hasil analisis struktur naratif dapat dibandingkan untuk melihat perubahan fungsi yang dilihat dari kernel dan satelit novel ke film 99 Cahaya di Langit Eropa melalui tinjauan intertekstual film terhadap novel aslinya.

\section{Metode Penelitian}

Dalam suatu penelitian diharuskan adanya metode yang tepat. Hal ini disebabkan berhasil tidaknya suatu metode penelitian tergantung pada pemilihan metode. "Metode penelitian adalah cara yang digunakan peneliti dalam mengumpulkan data penelitiannya," (Arikunto,2010:160). Sedangkan menurut Endraswara 
(2011:8), "Metode penelitian sastra adalah cara yang dipilih oleh peneliti dengan mempertimbangkan bentuk, isi, dan sifat sastra sebagai subjek kajian.

Metode yang digunakan dalam penelitian ini adalah metode deskriptif.Menurut Syam (2011:11), penggunaan metode deskriptif dalam penelitian sastra disebabkan data yang akan diolah berupa kata-kata,kalimatkalimat,integrasi dari kata dan kalimat, dan aspek kebahasaan yang tidak memiliki referensi.

Bentuk penelitian yang akan digunakan dalam penelitian adalah kualitatif.Menurut Moleong (2013:6).Penelitian kualitatif adalah penelitian untuk memahami fenomena yang dialami oleh subjek penelitian secara holistik dan dengan cara deskripsi dalam bentuk kata-kata dan bahasa pada suatu konteks khusus yang alamiah dengan memanfaatkan berbagai metode ilmiah.Metode yang digunakan dalam penelitian ini adalah metode deskriptif kualitatif.

\section{Hasil danPembahasan}

Kernel dan Satelit Novel 99 Cahaya di

\section{Langit Eropa}

Kernel dan satelit novel 99 Cahaya di Langit Eropa akan diuraikan berdasarkan hasil analisis.

Cerita 99 Cahaya di Langit Eropa diawali dengan kepergian Hanum ke Wina menyusul suaminya yang sedang Studi S3, dalam mengisi kesendirian Hanum, Ia mengambil kursus singkat bahasa Jerman di sinilah dimulai pertemuan Hanum dan Fatma yang akan menggerakan cerita ini Hanum mengenal Fatma di tempat kursus bahasa Jerman. Pertemuan Hanum dan Fatma mulai perjalanan Hanum mengelilingi negara Eropa (kernel 1).

Kernel 2 merupakan awal perjalanan Hanum mengelilingi Eropa, perjalanan Hanum dan Fatma dimulai menuju bukit Kahlenberg, di mana bukit Kahlenberg memiliki kecantikan yang sangat menakjubkan selanjutnya Hanum dan Fatma serta Ayse mampir ke kafetaria untuk beristirahat di kafe tersebut. Mereka bertemu dengan turis yang menghina Islam melalui roti croissant, Hanum sangat marah kepada turis tersebut. Tetapi Fatma mencegahnya. Fatma membalas semua perlakuan turis tersebut dengan membayari makanan mereka, lalu Fatma meninggalkan pesan kepada turis tersebut dan mencantumkan emailnya, besar harapan suatu saat nanti turis tersebut akan menghubungginya.

Kernel 3,4 perjalanan Hanum mengelilingi kota Wina, Hanum di ajak Fatma mengunjungi restoran Deewan yang berkonsep makan sepuasnya bayar 
seikhlasnya. Di sini yang dibutuhkan kejujuran pelanggan. Pelanggan restoran boleh makan sepuasnya lalu ketika akan membayar semua diserahkan kepada pelanggan tersebut.

Kernel 5,6 menampilkan kunjungan Hanum ke istana Schoenbrunn, dan dilanjutkan ke musium Wien, di museum Wina Hanum dan Fatma melihat lukisan Kara Mustafa Pasha yang ternyata masih mempunyai hubungan darah dengan Fatma, Kara Mustafa Pasha mempunyai perjalanan hidup yang tidak menyenangkan sehingga dijuluki penjahat.

Kernel 5 dan 6 merupakan babak yang menyebabkan Asye merasa minder, karena selalu diejek temannya karna merupakan keturunan Kara Mustafa Pasha.

Kernel 7 menceritakan ajakan Fatma kepada Hanum untuk mengunjungi kediaman Fatma di sana Hanum bertemu dengan Latife, Ezra dan Oznur. Hanum diminta menjadi mentor bahasa Inggris untuk mengajari mereka, dan mereka membuat misi menebarkan pesan perdamaian melalui ajaran Islam.

Kernel 8,9 menampilkan rencana Hanum ke Paris, Cordoba dan Granada, Istanbul. Dan dilanjutkan Fatma mengajak Hanum menonton bola Turki vs Spanyol.
Kernel 10 merupakan kernel yang selalu menyebabkan Hanum teringgat akan Fatma dan pada kernel 10 ini Fatma mengirimkan sms ke Hanum bahwa ia akan kembali keTurki, Hanum merasa kehilangan.

Kernel 11 menampilkan kunjungan Hanum dan Rangga ke VienaIslamic Centre. Di kernel 11 ini Rangga berkesempatan sholat di Viena Islamic Centre. Dan juga berkesempatan bertemu dengan Imam Hashim dan Imam Hasim memberikan kartu nama Marion Latimer yang tinggal di Paris,Prancis.

Kernel

menceritakan kedatangan Hanum dan Rangga ke Paris, di Paris mereka bertemu dengan Marion Latimer yang akan menjadi guide Rangga dan Hanum selama di Paris. Kernel 12 menyebabkan munculnya Kernel 13,14,15 karena dalam mengelilingi Marion Latimer lah yang selalu menemani Hanum. Pada karnel 13 Hanum diajak mengelilingi musium Louvre di musium itu, Hanum melihat sebuah piring makan kuno yang bertuliskan arab kuno, lalu perjalanan mereka di lanjutkan ke departemen melihat lukisan Monalisa dilanjutkan ke Painting Departemant Denon Wing.

Kernel 16 menceritakan misteri lukisan bunda Maria yang ternyata di hijab bunda Maria bertuliskan pseudo 
kufic (insripsi Arab) dan tulisan itu ternyata berbunyi " laa Illaa ha Illallah" yang merupakan kalimat sakral bagi umat Islam.

Kernel $\quad 17,18,1,20$ menggerakkan Kernel 18,19,20 yang merupakan perjalanan spiritual Hanum mengelilinggi negara Paris, yang dimulai mengunjungi monumen $\operatorname{Arc} d e$ Triomphe di lanjutkan ke Le Grande Mosquee de Paris lalu Huncback of Notre Dame ( Gereja Notre Dame).

Kernel 21 menceritakan mitos point zero (titik nol kota Paris) yang legendaris yang mengatakan siapapun yang menginjak plat logam. Dia pasti akan kembali ke kota Paris.

Kernel 22 menceritakan konflik yang terjadi di kampus Rangga yang mana ujian di kampus Rangga bertepatan dengan sholat Jum'at lalu perseteruan Khan dan Stefan.yang selalu bertengkar tentang kari.

Kernel 23 Merupakan keingintahuan Stefan tentang Islam yang selama ini mereka selalu berdebat tentang agama Islam akhirnya Stefan mengikuti Rangga untuk berpuasa walaupun pada akhirnya Stefan tidak kuat menyelesaikan puasa sampai Magrib.

Kernel 24,25,26 merupakan penggerak ke kernel 26 karena perjalanan selanjutnya menuju ke Cordoba dan Granada.

Kernel 27 menceritakan perjalanan Hanum mengunjungi Mezquita kernel ini menceritakan sejarah Mezquita dimana dulu adalah sebuah masjid dan sekarang menjadi gereja, konflik di kernel ini. Ketika Hanum di larang petugas untuk sholat di Mezquita.

Kernel 28 perjalanan Hanum ke Granada yang dimulai dari Gate of Justice menuju ke charles's palace lalu ke masrid palace dam terakhir ke istana Al Hambara yang di temani tour guide Luiz. Di perjalanan ini Hanum banyak mendapat pengetahuan dari perjalanan spiritualnya ( Kernel 28).

Kernel 29 merupakan pengerakan ending cerita 99 Cahaya di Langit Eropa, Kernel 29 menceritakan tentang keterkejutan Hanum mendapat email dari Fatma Pasha dan lebih mengejutkan Fatma menceritakan bahwa Asye telah meninggal dunia dikarenakan kanker yang di idapnya.

Kernel 30 menceritakan kedatangan Hanum di Istanbul untuk menemui Fatma. Pada kernel 30 ini mengambarkan keterkejutan Fatma melihat Hanum memakai hijab. Pada kernel ini Fatma mempunyai seorang bayi berusia 3 bulan penganti Asye yang bernama Baran. 
Pada kernel ini juga menceritakan usaha Fatma membuka usaha butik dan jahitan dan yang lebih mengembirakan lagi, Fatma Hanum mendapat email dari orang yang menghina Turki pada saat di Kahlenberg tentang roti Croissant.

Kernel 31 merupakan ending dari cerita novel 99 Cahaya di Langit Eropa, pada kernel ini merupakan kontemplasi dari Hanum yang ternyata Hanum setelah perjalananya mengelilingi Eropa Hanum menunaikan ibadah haji sendiri walaupun Rangga tidak dapat menemani karena jadwal mengajar yang padat. Dan Hanum berharap semoga cahaya Islam selalu menyinari dunia.

Berdasarkan kernel 1 sampai 31 dapat disimpulkan bahwa kernelkernel terjalin secara Linear atau berurutan di mana kernel-kernel tersebut menimbulkan cerita yang selanjutnya yang membuat jalan cerita (alur) disampaikan dari awal sampai akhir.

Kernel dan Satelit Film 99 Cahaya di Langit Eropa

Kernel dan Satelit Film 99 Cahaya di Langit Eropa akan diuraikan berdasarkan hasil analisis.

Film 99 Cahaya di Langit Eropa diawali dengan kedatangan Hanum dan Rangga di Eropa, dan kesulitan mereka mencari makanan yang halal, dan kesulitan buat Hanum mencari pekerjaan apabila tidak bisa berbahasa Jerman (Kernel 1) adalah awal cerita film 99 Cahaya di Langit Eropa

Kernel 2 menampilkan perdebatan antara Rangga Stefan, yang selalu memperdebatkan makanan haram dan halal, dan larangan sholat di kampus.

Hanum mengikuti kursus Bahasa Jerman, disinilah awal pertemuan Hanum dan Fatma dan Ayse (Kernel3). Kernel 3 ini merupakan awal perjalanan spiritual Hanum mengeliling Eropa.

Dilema yang dialami Rangga karena waktu sholat Jum'at pukul 12.0014.00. kernel 4 inilah yang menjadi dilema buat Rangga.

Kernel 5 menceritakan konflik yang terjadi antara Hanum dan tetangganya yang merasa terganggu dengan masakan Indonesia. Kernel ini menceritakan bagaimana marahnya tetangga Hanum.

Kernel 6 menceritakan kunjungan Fatma,Hanum dan Ayse ke bukit Kahlenberg yang menawan, kernel ini adalah penyebab terjadinya kernel 7 dimana terjadi insiden Croissant yang membuat Hanum sangat marah kepada turis tersebut dan Fatma malah sebaliknya berlaku kepada turis tersebut, 
Fatma membayari makanan turis tersebut, dan Fatma memberikan konsep bagaimana menjadi agen muslim yang baik.

Kernel 8 menampilkan konflik lukisan Kara Mustafa di Musium Wina, ternyata Fatma Pasha masih keturunan Kara Mustafa Pasha. Kernel 8 ini menyebabkan Ayse diolok-olok oleh teman sekelasnya karena masih keturunan Kara Mustafa Pasha dan berhijab.

Kernel 9 menceritakan kunjungan Hanum ke rumah Fatma, di rumah tersebut Hanum bertemu dengan teman-teman Fatma yaitu Latife, Ezra,dan Oznur. Hanum mengajari mereka Bahasa Inggris, dan mereka mempunyai misi menjadi agen muslim yang baik

Kernel 10 menampilkan Rangga dan Khan melaksanakan Sholat Jum'at, sholat Jum'at tersebut dilaksanakan bertepatan dengan jadwal ujian mereka.

Kernel 11 menceritakan pertemuan Hanum, Rangga dengan Hasyim (Imam di Masjid Wina) pada kesempatan tersebut Rangga melaksanakan. sholat di masjid tersebut.

Kernel 12 menceritakan permintaan maaf turis pada kejadian Insiden Croissant, turis tersebut mengirimkan email permintaan maaf kepada Fatma. Fatma merasa senang karena cara yang dia pakai berhasil.

Kernel 13 menampilkan ajakan Fatma mengunjungi restoran dengan konsep ikhlas Dee Wiener Deewan. Di mana di restoran tersebut kita bisa makan sepuasnya bayar seikhlasnya, disini konsepnya mengandalkan kejujuran. Fatma memberikan kartu nama temannya yang bernama Marion Latimer yang tinggal di Paris. Kernel 13 ini merupakan babak yang menuju kernel selanjutnya.

Kernel 14 menceritakan perjalanan Hanum dan Rangga ke Paris. Pada kernel ini menceritakan pertemuan Rangga dan Hanum dengan Marion Latimer. Pada kernel ini menceritakan perjalanan Hanum dan Marion mengunjungu Museum Louvre. Hanum melihat tulisan Arab di kerudung Bunda Maria. Hanum dan Rangga menaiki menara Eiffel sampaike lantai 3, tergetar hati Rangga untuk mengumadangkan azan dari puncak menara Eiffel.

Kernel 15 pada kernel ini menceritakan keinginan Stefan mengikuti Rangga untuk berpuasa. Kernel 15 ini menceritakan ketidakmampuan stefan menyelesaikan puasa sampai Magrib.

Kernel 16 diceritakan bahwa Hanum kehilangan Fatma, karena Fatma tidak menghadiri pembagian sertifikat 
kursus bahasa Jerman, Hanum mendatangi rumah Fatma tapi Ia tidak berada di rumah.

Kernel 17 adalah keinginan Rangga dan Hanum untuk mengunjungi Cordoba, kernel 17 adalah penggerak kernel selanjutnya.

Pada karnel 18 diawali dengan menceritakan masa kecil (lalu) yang selalu disuruh oleh orang tuanya untuk selalu belajar, tetapi Khan kecil ingin berperang dan pada akhirnya Khan menuruti kemauan orang tuanya.

Kernel 19 menceritakan tentang 3 orang muslim yang ingin sholat di Mezquita (tempat perkembangan Islam di Eropa) Kernel 20 menampilkan bahwa Hanum teringat akan Fatma.

Kernel 21 memunculkan konflik yang membuat Rangga bingung dengan ajakan Maria ke pesta dansa, kernel 21 yang menyebabkan munculnya kernel 22, dimana ketika Hanum membawa kue ulang tahun dirinya(kebetulan pada saat itu Hanum berulang tahun). Hanum melihat kedekatan Rangga dan Maria padahal semua itu tidaklah sengaja, hal inilah yang menyebabkan keributan antara Hanum dan Rangga, tetapi kesalahpahaman itu dapat diselesaikan dengan baik. (Kernel 23)

Misi Rangga untuk mendamaikan Khan-Stefan, tetapi misi Rangga masih perlu perjuangan untuk

mendamaikan mereka (Kernel 24). Pada Kernel 25 Hanum mengizinkan Rangga untuk mengikuti pesta dansa.

Kernel 26 menceritakan perjalanan Hanum dan Rangga ke Cordoba, mereka mengunjungi Mezquita, peristiwa Hanum yang ditegur oleh petugas, bahwa boleh bersujud di Mezquita, cerita Mezquita yang dulu adalah sebuah masjid berubah menjadi gereja. Kernel 26 menggerakkan kernel 27, Rangga lupa membooking hotel, alhasil Rangga dan Hanum menghabiskan malam di jalan ditemani sinar lampu di kota Cordoba.

Kernel 28 Khan mendapat telepon dari uminya yang mengabarkan bahwa ayahnya meninggal. Pada kernel 28 ini muncul konflik antara Khan, Stefan dan Rangga. Stefan tidak terima khan dan Rangga bertukar jadwal ujian. Kernel 29 dan kernel 30 pertemanan antara Stefan dan Khan, pada kernel 29 menceritakan tentang Stefan dan khan yang membantu Stefan ketika ditabrak sebuah mobil, Khan yang mengurus segala urusan adminstrasi Stefan. Sedangkan pada kernel 30 akhirnya Khan dan Stefan berteman baik.

\begin{tabular}{lcr}
\multicolumn{1}{c}{ Kernel } & 31 & menceritakan \\
keberhasilan & Rangga & dalam \\
menyelesaikan kuliah & S3-nya, Rangga \\
diminta memberikan & pidato diacara \\
wisuda tersebut.
\end{tabular}


Kernel 32 menyebabkan munculnya kernel 33. Pada kernel 32 Hanum mendapat email dari Fatma, dan itu sangat mengejutkan Hanum, kernel 33 menceritakan kepergian Hanum dan Rangga ke Istanbul menemui Fatma, Hanum akhirnya bertemu dengan Fatma, ternyata Fatma sedang mengandung 3 bulan. Fatma mengajak Hanum dan Rangga mengunjungi Haga Shopia.

Kernel 34, 35 merupakan ending dari film 99 Cahaya di Langit Eropa. Kernel 34 menceritakan tentang Ayse, ternyata Ayse telah meninggal dikarenakan kanker yang diidapnya, betapa terkejutnya Hanum mendengar cerita Fatma, dan akhirnya Fatma mengajak Hanum berziarah ke makam Ayse. Kernel 35 adalah kotemplasi Hanum, Hanum akhirnya menggunakan jilbab untuk pertama kalinya di makan Ayse, untuk memenuhi janjinya kepada Ayse.

Cerita diakhiri dengan narator menceritakan kepergian Hanum melaksanakan ibadah haji ke tanah suci dan Rangga menjadi dosen di

UGM (kernel 36,37).

Berdasarkan pembahasan di atas, kernel yang terdapat dalam film 99 cahaya di langit berjumlah 40 kernel dan memiliki 70 satelit. Alur yang digunakan dalam film ini adalah alur maju dimana kernel 1 menyebabkan terjadinya kernel 2 dan seterusnya, walaupun ada pemotongan sub adegan yang menggantung yang terlihat ada kernel 4 dan 5. Dan kernel 11 dan kernel 12. Pada intinya pemotongan sub-sub film tersebut tidak mempengaruhi jalannya cerita, karena penonton masih bisa mengikuti alur ceritanya.

Perbedaan yang terjadi akibat perubahan fungsi yang terjadi pada film terhadap novel hipogramnya dapat dijelaskan sebagai berikut.

Perbedaan 1 pada awal penuturan alur film, menampilkan dialog antara Ayse dan gurunya yang membahas tentang hijab yang dipakai Ayse, Ayse selalu diolok-olok oleh Leon tentang hijabnya, sedangkan pada novel menceritakan langsung tentang perjalanan Hanum dan Fatma menyusuri sudut-sudut kota Wina.

Perbedaan 2 pada film menampilkan Alur perkenalan dengan Fatma, sedangkan pada novel Fatma dan Hanum diceritakan telah terlibat obrolan yang seru tentang kota Wina. Selanjutnya pada film mulai mengenalkan tokoh-tokoh seperti Stefan, Marjaa dan Khan.

Perbedaan 3 alur konflik film menampikan Insiden Croissant secara singkat sedangkan dalam novel diceritakan Insiden Croissant secara 
detil. Perbedan Keempat dalam film dijelaskan dilema yang dialami Rangga tentang waktu sholat Jumat yang selalu bersamaan dengan waktu ujian wajib, yaitu pada Jumat pukul 12.00-14.00, sedangkan di bovel tidak diceritakan.

Perbedaan 5 yang terjadi pada film adalah pada film ditampilkan Rangga pernah dipermainkan oleh seorang pelayan kantin karena meminta makanan halal, yang menurut pelayan kantin sungguh aneh dan merepotkan, sedangkan pada novel alur tersebut tidak diceritakan.

Perbedaan 6 adalah tahapan konflik pada film dan novel, pada film diceritakan bagaimana Hanum meninggalkan kariernya di Indonesia dan sempat menganggur di Wina, sedangkan pada novel tidak diceritakan. Perbedaan 7 yaitu pada film ditampilkan Hanum mendapat protes dari tetangga di apartemennya karena sering memasak masakan Indonesia yang bagi si tetangga, baunya sangat mengganggu.

Konflik yang terjadi di perbedaan 8 film dan novel adalah pada film menampilkan Rangga yang selalu dihadapkan pada pertanyaanpertanyaan filosofis yang diajukan kawannya, seorang atheis. Perbedaan kesembilan pada film menampilkan
Stefan yang ikut berpuasa dan sholat Jumat bersama Rangga, sedangkan pada novel tidak diceritakan hal tersebut.

Perbedaan 10 merupakan konflik yang ditampilkan film dan novel adalah pada film menampilkan ketika Hanum disindir oleh seorang anak mengapa Hanum tidak memakai hijab padahal mengajarkan Al-Qur'an di perkumpulan pengajian, di novel peristiwa tersebut tidak diceritakan.

Klimaks pada film diceritakan bagaimana keributan yang terjadi antara Khan dan Stefan yang mempersoalkan masalah makanan halal dan haram, sedangkan di novel tidak diceritakan secara detil hanya garis besarnya saja, dan ini merupakan perbedaan yang ke-11. Perbedaaan selanjutnya pada film Hanum melihat seorang bule yang senang sekali belajar islam dan akhirnya mengucapkan dua kalimat syahadat, dinovel tidak disinggung sama sekali permasalahn itu (perbedaan 12).

Rangga yang berkali-kali diajakikut pesta oleh kolega perempuannya (Marjaa) dan kolega tersebut selalu mencari-cari kesempatan untuk seolah-olah minta bantuan masalah disertasi di perpustakaan. Ini terjadi sebelum Marjaa tahu Rangga telah menikah, 
sedangkan dinovel tdak diceritakan ketertarikan Marjaa kepada Rangga (perbedaan13).

\begin{tabular}{cccr}
\multicolumn{2}{c}{ Perbedaan } & 14 & adalah \\
perbedaan yang terjadi & pada
\end{tabular}
pemberian kartu nama Marion Latimer kepada Hanum, yang terjadi pada film kartu nama diberikan oleh Fatma sendiri, sedangkan pada novel yang memberikan adalah Imam Hashim.

Selanjutnya perbedaan yang terjadi adalah di film ditampilkan cerita masa kecil Khan yang mana orang tuanya menginginkan Khan berjihad melalui pendidikan tapi Khan kecil tidak mau menuruti kemauan ayahnya, dan pada akhirnya Khan menuruti kemauan ayahnya, di novel tidak diceritakan hal tersebut (perbedaan 15).

Selanjutnya di novel tidak diceritakan kecelakaan Stefan sama sekali. sedangkan di film diceritakan secara detil jalan cerita Stefan mengalami kecelakaan, kecelakaan Stefan itulah yang menyebabkan pertemanan antara Stefan dan Khan (perbedaan 16).

Perbedaan 17 yaitu tentang di novel tidak diceritakan bagaimana Ayse meninggal dunia sedangkan di film ditampilkan cerita detil bagaimana Ayse mengalami koma dan akhirnya meninggal. Pada perbedaan

18 Rangga pada film ditampilkan mengumandangkan azan dilantai 3 Menara Eifell sedangkan pada novel tidak diceritakan hal tersebut.

Hanum dan Rangga bermalam di jalanan dikarenakan Rangga lupa memesan hotel untuk mereka sedangkan di novel tidak diceritakan, perbedaan ini adalah perbedaan ke-19. Perbedaan Selanjutnya adalah keributan yang terjadi antara Hanum dan Rangga yang disebabkan Hanum marah kepada Rangga yang terlihat sedang bermesraan dengan Marjaa, alur cerita ini diceritakan di film , sedangkan dinovel tidak diceritakan sama sekali (perbedaan 20).

Perbedaan 21 dimana di film ditampilkan kalau Fatma sedang mengadung tiga bulan, sedangkan di novel Fatma diceritakan sudah memiliki anak berusia tiga bulan yang bernama Baran. Perbedaan yang terakhir (perbedaan 22) adalah ending dari cerita film dan novel yang tidak sama, pada film ditampilkan kontemplasi Hanum memakai hijab dihadapan makam Ayse sedangkan dinovel jalan cerita tersebut tidak seperti itu. Pada novel Hanum memakai hijab ketika bertemu dengan Fatma.

Berdasarkan

perbedaan alur (jalan cerita) 
didapatkan perbedaan sebanyak 22 perbedaan jalan cerita ( alur), yang terjalin membentuk rangkaian cerita. Perbedaan yang terjadi antara alur cerita novel dan film tidak menyebabkan berbedanya struktur dan jalinan cerita. Cerita dijalin secara logis walaupun ada alur (jalan cerita) yang berbeda atau tidak ada sama sekali. Hal ini dikarenakan media yang berbeda, novel menggunakan bahasa tulis (verbal), sedangkan film lebih menekankan bahasa visual melalui ekspresi, gestur dan penghayatan.

\section{Kesimpulan}

Berdasarkan data yang telah diperoleh dalam penelitian ini "Transformasi Novel ke Film 99 Cahaya di Langit Eropa karya Hanum salsabila dan Rangga Almahendra” dapat disimpulkan sebagai berikut, (1) kernel dan satelit yang terdapat dalam novel 99 Cahaya di Langit Eropa adalah terdapat 31 kernel dan 62 satelit, sedangkan (2) kernel dan satelit yang terdapat dalam film 99 Cahaya di Langit Eropa adalah sebanyak 40 kernel dan 70 satelit, dan (3) perbedaan tahapan alur yang terdapat dalam novel dan film 99 Cahaya di Langit Eropamengalami perubahan modifikasi (penyesuaian cerita) ekspansi (perluasan atan pengembangan cerita) dan haplologi (pengurangan atau penghilangan cerita) dan terdapat 22 perbedaan alur (jalan cerita).

Saran

Berdasarkan penelitian tranformasi novel dan film 99 Cahaya diLangit Eropa, peneliti berharap semoga pada penelitian selanjutnya, akan ada penelitian-penelitian yang lain, dan bisa lebih mengembangkan lagi transformasi novel dan film.

Penelitian ini diharapkan memberikan pengayaan kepada masyarakat mengenai karya Hanum Salsabilah,yaitu novel berjudul 99 Cahaya di Langit Eropa yang telah mengalami perubahan bentuk melalui medium lain yaitu audio visual berupa film dengan judul yang sama. Dengan demikian, melalui pengayaanpengayaan tersebut diharapkan mampu menumbuhkan apresiasi dan penghargaan masyarakat terhadap hasil dan bentuk karya seni, baik berupa karya sastra maupun fillm.

\section{DAFTAR PUSTAKA}

Aminudin. 1990. Sekitar Masalah

Sastra: Beberapa Prinsip dan

Masalah Perkembangan.

Malang: YA3 Malang.

Arikunto,Suharsimi.1998.Prosedur

Penelitian Suatu Pendekatan

Praktek.Jakarta; Rineka Cipta..

Chatman, Seymour. 1980. Story and

Discourse:

Narrative 
Structure in Fiction and Film.

Ithaca.

Culler, Jonathan.

1981.

The Pursuit of Signs :

Semiotics,

Literature, Deconstructure. $\mathrm{Ne}$

w York: Cornell University Press.

Endraswara, Suwardi.2011.Metodologi

Penelitian Sastra.Jakarta:PT

Buku Seru

Eneste, Panusuk. 1991. Novel dan Film.

Flores: Penerbit Nusa Indah.

Faruk. 2003. Pengantar Sosiologi

Sastra. Yogyakarta. Pustaka

Pelajar.

Nurgiyantoro, Burhan. 2000. Teori

Pengkajian Fiksi. Yogyakarta.

Gadjah Mada University Press.

Ratna, Nyoman Kutha. 2006. Teori,

Metode, dan Terbaik
Penelitian Sastra. Yogyakarta:

Pustaka Pelajar.

Salsabillah,Hanum dan Rangga

Almahendra.2013.99 Cahaya di

Langit Eropa.Jakarta:Cv Prima

Grafika

Sani, Asrul.1997. Surat -

Surat Kepercayaan

. Bandung:

Tarigan, Henry Guntur. 1984. Prinsip-

Prinsip Dasar Sastra.

Bandung:Angkasa.

Teew, A. 1998. Sastra dan

$\begin{array}{lr}\text { Ilmu } & \text { sastra. } \\ \text { Jakarta: } & \text { Pustaka } \\ \text { Jaya. } & \end{array}$

Wellek, Rene \& Austin Waren. 1989.

Teori Kesusastraan . Di

Indonesiakan oleh Melani

Budianta. Jakarta : Gramedia. 